\title{
Smart Body Temperature Monitoring system for Children Via Mobile
}

\author{
Annie anak Joseph \\ Department of Electrical and Electronics, \\ Faculty of Engineering, \\ Universiti Malaysia Sarawak \\ 94300, Kota Samarahan, Sarawak \\ jannie@unimas.my \\ Timothy Huang Li Xuan \\ Department of Electrical and Electronics, \\ Faculty of Engineering, \\ Universiti Malaysia Sarawak \\ 94300, Kota Samarahan, Sarawak \\ thlx blue@hotmail.com
}

\author{
Kuryati Kipli \\ Department of Electrical and Electronics, \\ Faculty of Engineering, \\ Universiti Malaysia Sarawak \\ 94300, Kota Samarahan, Sarawak \\ kkuryati@unimas.my \\ Kho Lee Chin \\ Department of Electrical and Electronics, \\ Faculty of Engineering, \\ Universiti Malaysia Sarawak \\ 94300, Kota Samarahan, Sarawak \\ lckho@unimas.my \\ Ngu Sze Song \\ Department of Electrical and Electronics, \\ Faculty of Engineering, \\ Universiti Malaysia Sarawak \\ 94300, Kota Samarahan, Sarawak \\ ssngu@unimas.my
}

\begin{abstract}
Health monitoring system has been an interesting topic recently among medical practitioners, engineers as well as IT professionals [1]-[2]. However, the application of automatic temperature monitoring system where parents can monitor the temperature of their children is practically new in Malaysia and other countries. Babies are much more sensitive to high body temperature and any occurrence of fever has to be taken very seriously. Smart body temperature monitoring system for baby and infant is beneficial to the parents where such implementation will help parents to save their energy and time. The objective of this project is to design and develop smart body temperature measurement device that can be observed by the parents for monitoring children body temperature over the time especially night time in case of abnormalities or having high fever. In the proposed method, body temperature wireless sensors is developed. The target of user of this device is children under age of five. This project develops a monitoring method which benefit parents and children by lessen anxiety of parents while ensure the children body temperature is under dangerous level. The prototype showed the temperature reading was successfully receive on the android application. The temperature measurements were validated with Rossmax TG100 with a difference of plus minus 0.5 degree celcius . The temperature sensors will send the readings to one device and triggered the system alarm when the body temperature is exceed the threshold. With this device, the temperature of the children can be monitored automatically over the night and alert to the parents once the reading is triggered.
\end{abstract}

Keywords-body temperature; health monitoring system, children, smart device, mobile

\section{INTRODUCTION}

In 2016, 2.6 million children died in the first month of life which is approximately 7000 new-born deaths every day [3]. According to Institute for Health Metrics and Evaluation, Malaysia mortality trend in the under age of five and under one age group are 6.0 percent and 4.7 percent of the total mortality population respectively. 8.2 million children under age of five died every year and $30 \%$ of them suffered pneumonia or rotavirus [4]. Pneumonia claims a child's life every 20 seconds. Pneumonia is caused by infection of certain bacteria such as Mycoplasma pneumoniae and Chlamydophila pneumonia. Children who suffer from pneumonia have symptoms like high fever, flushed skin, sweating, difficulty to breath and wheezing. Children are more vulnerable to infection since their immune system is not fully developed. In this modern society, type of infections is getting more and more serious. Protozoa, viruses, fungi, prions and bacteria are different type of pathogen. They are different in their shape, function, genetic content and their effect towards body. The viruses are smaller than bacteria which they can enter a host and control cells, but bacteria can live without a host. Children under age of five are more invulnerable to infections. The most common indicator of infection is fever. Fever is a condition where subject has high body temperature than usual temperature. It is not an illness but a symptom of an underlying condition, mostly an infection. 